\title{
La reconfiguración del Departamento de Historia en el marco de la Facultad de Humanidades y Ciencias
}

Luciano Alonso (1)

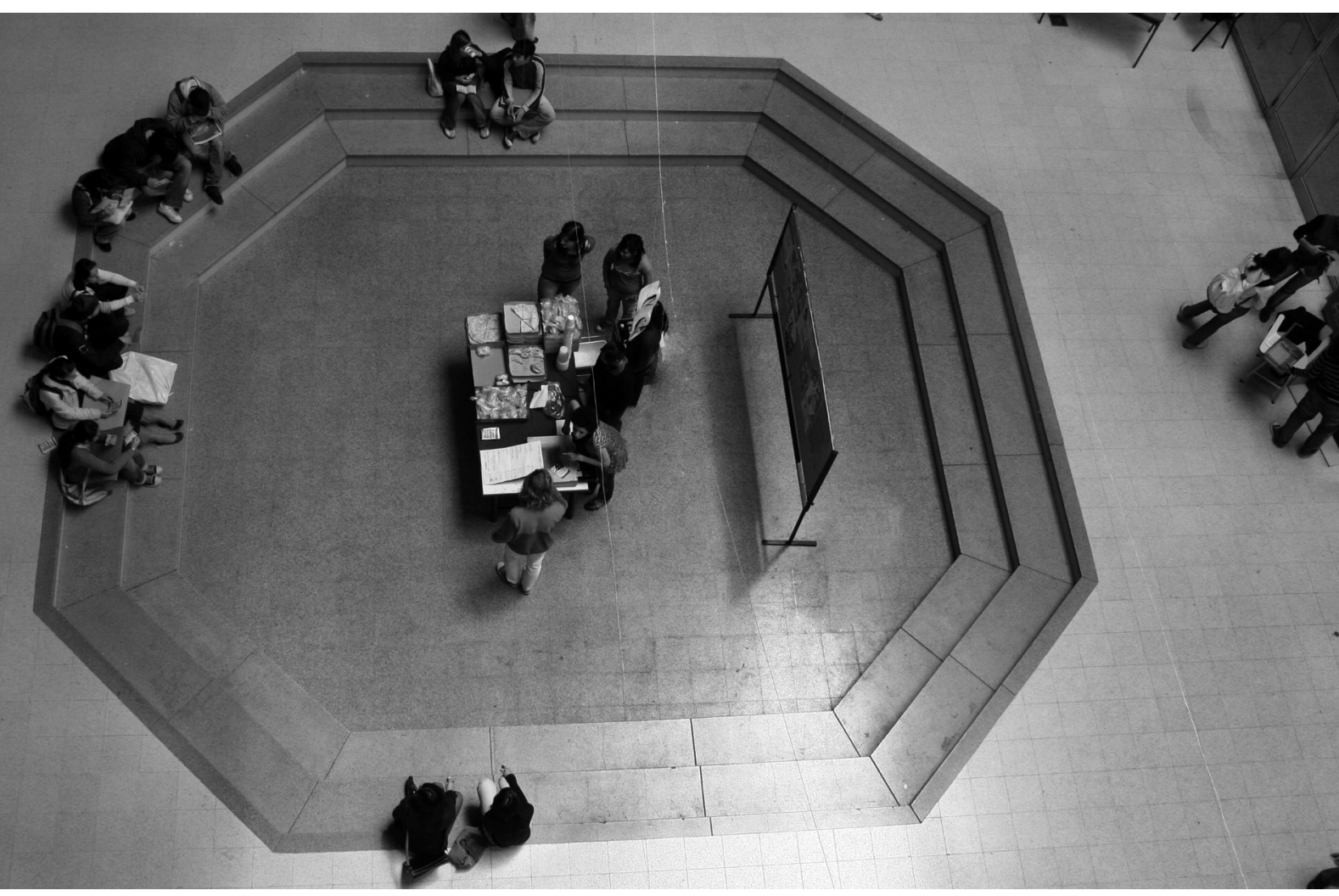

(1) Ex Director del Departamento de Historia de la Facultad de Humanidades y Ciencias, Universidad Nacional del Litoral.
Agradezco los oportunos comentarios de Nélida Diburzi, Alberto Bartolini y José Larker, que naturalmente no son responsables por las opiniones vertidas en este escrito. 
Como frecuente demostración de que nunca hay una evolución lineal y progresiva, en la historia de las instituciones suelen producirse mutaciones, quiebres, desarticulaciones o nuevas configuraciones. Dar cuenta del desarrollo de un área como el Departamento de Historia en los veinte años de la Facultad de Humanidades y Ciencias supone entonces registrar ciertos cambios o alteraciones más que una reseña de actividades acumuladas. 0 incluso mirar hacia etapas anteriores para señalar qué es aquello que se ha superado o que más frecuentemente se ha perdido. Como además el período de formación y afianzamiento de la Facultad se superpone con mi experiencia profesional como docente e investigador, realizada casi enteramente en esta institución, se me disculpará que en mi reseña apele más a la propia memoria que a las constancias de una indagación y que además lo haga en un acusado y seguramente impropio tono de implicación personal.

De inicio, una constatación. La historia como disciplina específica que fundara una práctica de producción de conocimiento había sido en gran medida expurgada de la Universidad Nacional del Litoral en las décadas de 1960 y 1970. De los últimos años cincuenta provenía la formación del Instituto del Profesorado Básico y la separación de la unidad académica respecto de la entonces Facultad de Filosofía, Letras y Ciencias de la Educación con sede en Rosario. Eso no supuso un divorcio respecto de los profesionales radicados en las unidades de investigación rosarinas, que estuvieron al frente de cátedras específicas en Santa Fe -con los vaivenes habituales en estas tierras- hasta 
inicios de la década del '70. Pero la formación de la Universidad Nacional de Rosario sí generó un mayor distanciamiento. A mediano plazo, se debilitaron o diluyeron los vínculos con grupos de estudios especializados y los desarrollos historiográficos del sur provincial parecieron algo ajeno a la experiencia santafesina, al punto que aún hoy en la Biblioteca de nuestra Facultad ni siquiera se encuentran todos los ejemplares de su Anuario de Historia.

Pero mucho más brutalmente, ese expurgo de la historia se produjo con las cesantías directas o encubiertas, con las renuncias y los alejamientos que caracterizarían a la etapa de terror de Estado abierta en 1974 y profundizada desde 1976 por la dictadura militar. Un breve repaso a las resoluciones de cese de docentes o de reorganización institucional puede dar cuenta de la progresiva eliminación de toda vía para el sostenimiento de una labor historiográfica o, aún más, de toda posición crítica. El que los profesorados específicos vinieran a reemplazar al Profesorado de Castellano y Ciencias Sociales, en un proceso en el que se solapan las decisiones tomadas en diversos momentos de los gobiernos constitucional y dictatorial, no puede ocultar el profundo vaciamiento del cuerpo docente y la desestructuración de los equipos de cátedra que conspirarían contra toda posibilidad de afianzamiento de la disciplina.

En lo que a mí respecta, ingresé como estudiante a la carrera de Profesorado en Historia en la segunda mitad de la dictadura. Ya habían pasado los momentos más duros, los conflictos y represiones cuyos detalles conocería por varios compañeros de mayor edad. Si el término "burocrático-autoritario" tiene algún viso de aplicación a los regímenes de terror de América Latina, sería precisamente en alusión a la normalidad institucional de esos años de dictadura más atemperada, primero en reacomodamiento, luego en ordenada retirada.

Teníamos a cargo de las aulas algunos personajes como quién tiempo después, ante un único y tímido desplazamiento de una cátedra operado por la gestión normalizadora, diría en marzo del '84 a su alelada auxiliar docente: "No te preocupés que vamos a volver, y vamos a volver de golpe". O aquella que en el punto máximo del dislate nos invitaba a integrarnos a un grupo de estudio aclarando que "somos de derecha, pero no somos nazis" (y yo nunca quise saber muy bien qué ni quiénes eran). Pero también tuvimos un generoso grupo de docentes que se puso al hombro una carrera. Profesoras que enseñaban 
aquello que no se suponía que se estudiara en plena dictadura, a veces a contrapelo de la normalidad imperante y en algún caso bordeando la crítica ácida de las formas institucionales. Que incluso nos pasaban con cierto sigilo y selectividad libros de autores interdictos como un hasta entonces desconocido por nosotros Rodolfo Puiggrós o nos instaban a leer a "Carlitos" (Marx), en un gesto que no podíamos menos que interpretar como de una complicidad en el conocimiento.

De la época inmediatamente anterior a la última debacle, sonarían hacia 198384 muchos nombres que actuaban como referentes para tender puentes hacia una reconstrucción de las tareas académicas. Pero tres profesoras en particular -dos de ellas ya fallecidas- aparecen como portadoras de un poderoso legado docente en el campo de la historia: Susana Simian de Molinas, Ruth Niklison e Hilda Puente. Con la primera hice un curso apenas acabada la dictadura en el cual aprecié su método retrospectivo; de la segunda aproveché sus traducciones de textos clásicos de la historiografía modernista y aprendí que se podía pensar en Europa desde Santa Fe con un sesgo creativo y crítico; de la tercera fui compañero de trabajo y estimé principalmente su profunda racionalidad y su apertura a la historia de los mundos no europeos. Aún hoy me impresiona el grado en el cual esas tres personas, de las que no fui alumno y a una de las cuales ni siquiera conocí, impactaron en mi formación de modos a veces muy indirectos. Junto con Ricardo Ahumada, con quien sí cursé y cuyos inmensos aportes son difíciles de resumir en una frase, constituyeron para mí -y para muchos de un "nosotros" siempre cambiante- una referencia ineludible.

Con esas o con otras experiencias a cuestas, el modelo institucional que se articulaba a la salida de la dictadura en la entonces Escuela Universitaria del Profesorado estaba fuertemente asentado en la docencia. A partir de allí, el proceso de conversión de la unidad académica en Facultad significó para el Departamento de Historia la (re)inauguración de una vía de desarrollo hacia la investigación y la extensión. Cuando se creó la Facultad con la denominación de Formación Docente en Ciencias en 1987, quedaba claro que el camino emprendido podía ir mucho más allá de ese perfil. Para ese entonces campeaban los más variados revisionismos, no íbamos a socializar ni siquiera la cultura y nos habían mandado a casa con un "felices Pascuas", así que más 
tarde o más temprano asumimos que la institución universitaria era un lugar en el cual volcar nuestras energías. Y un "lugar" fuerte, con toda la carga identitaria del término. El Departamento se había renovado con varias incorporaciones y con el reingreso de algunos de los docentes que habían participado como auxiliares o estudiantes en el período previo a la etapa de terror. Aunque fuera difícil partir de la inexistencia de centros de estudios y redes académicas, aunque los concursos fueran tardíos y aunque perdurara una cierta sensación de venir de la tierra arrasada y de estar en los márgenes del mundo, se podía emprender un nuevo tipo de labor.

Para ese entonces se realizaban las primeras Jornadas Interescuelas / Departamentos de Historia de Universidades Nacionales -hoy ya por la onceava edición- con aires de democratización de la disciplina y en el centro de un proceso de reconfiguración del campo historiográfico argentino. No era difícil inventar agendas allí donde todo estaba por hacer, lo más dificultoso fue construir objetos historiográficos viables e insertarse en el panorama nacional. Fueron surgiendo los primeros proyectos de investigación en el área disciplinar, primero validados por la misma Facultad y luego incorporados en los programas de la Secretaría de Ciencia y Técnica del Rectorado. De ese modo se fueron desarrollando en la unidad académica trabajos sobre historia política, estudios de género, estudios culturales, de historia social en distintas variantes y diversos abordajes teóricos, metodológicos y de historia de la historiografía. Una característica de ese abanico de producciones intelectuales ha sido en todo momento su entrecruzamiento mutuo y su interrelación con otras disciplinas, así como la transferencia a la docencia y la extensión. Debemos a personas como Darío Macor, Lidia Acuña y Teresa Suárez en el campo de la investigación, a Esther Pavetto en el de la docencia y a las dos últimas de las nombradas en el de la extensión, la renovación de las líneas de trabajo del Departamento de Historia. Con seguridad que fuimos muchos otros los que colaboramos en ese proceso y que constituye casi una injusticia omitir otros nombres. En última instancia las individualidades citadas no son más que emergentes de un trabajo colectivo, progresivamente afianzado en la institución universitaria y en el entramado de su gestión, al tiempo que acompañado por multitud de alumnos y graduados no rentados. 
Pese a esa creciente apertura a la producción de conocimiento socio-histórico, el transcurrir del Departamento en Historia estuvo marcado en estas dos décadas por las modificaciones de planes de estudios de 1991-1993 y de 2001. Intentos de abrir nuevos campos de trabajo, de acercar la historia al estudio de la contemporaneidad -de lo "reciente" o del "tiempo presente", preferimos algunos-, de romper con más o menos éxito los moldes canónicos de la disciplina. A veces también, incapacidades para articular mejor los esfuerzos en nuevas cátedras o en una interacción con otros espacios académicos, dificultades para repensar la formación de grado más allá de la lógica diacrónica y del eje europeo-occidental. Pero siempre con una gran densidad de tareas y una fuerte dedicación a la formación de profesores y licenciados. Incluso con el más reciente modelo de gestión, en el cual las Carreras se hallan funcionalmente separadas de los Departamentos, la preocupación por las cuestiones de la docencia universitaria ha sido constante. En ocasiones las tareas de extensión también han llevado a la vinculación con instituciones de otros niveles educativos en tanto que, con la dirección de Nélida Diburzi, se gestionaron desde el 2006 las Olimpíadas de Historia de la República Argentina. Por fin, muchas veces la definición de espacios docentes ha revertido en la apertura de líneas temáticas para nuevas indagaciones disciplinares.

Hoy los docentes-investigadores del Departamento de Historia participan de al menos cuatro centros de estudios y cuatro revistas periódicas radicadas en la Facultad, se desempeñan como integrantes de comités académicos o árbitros de diversas publicaciones, dirigen $y / 0$ integran unos ocho proyectos de investigación de variada definición radicados en distintas unidades y desarrollan unos tres proyectos de extensión. Aún en condiciones de carencia de cargos y recursos presupuestarios suficientes, en los últimos diez años el número de integrantes del Departamento se ha acrecentado en un $60 \%$. Hay tal vez un afianzamiento de la historia en la Universidad Nacional del Litoral, paradójicamente coexistente con la dilución de sus límites disciplinares respecto de otras ciencias sociales y a una creciente integración con otros actores académicos. Nos seguimos debiendo una mejor articulación con el medio social y con otras instituciones, al tiempo que nuestra labor específica es infinitamente perfectible. 
Aunque debamos evitar la complacencia y recordemos que la crítica más fructífera es aquella capaz de revertir sobre las propias posiciones, no podríamos hacer un balance negativo. El espacio institucional que integramos se ha consolidado. Los veinte años de historia de nuestra Facultad, hoy definida como de Humanidades y Ciencias, son una etapa trascendente en nuestro desarrollo profesional y en la constitución de un ámbito de producción y circulación de conocimiento socio-histórico renovado. Como toda construcción humana, como nosotros mismos, es un espacio no sólo sujeto a constantes mutaciones sino incluso perecedero. En consecuencia, no podemos menos que pensarlo en construcción permanente. 